\title{
HUBUNGAN PENDIDIKAN DAN PENGETAHUAN DENGAN PENGAMBILAN KEPUTUSAN KEPALA KELUARGA DALAM PERTOLONGAN PERSALINAN PADA IBU BERSALIN DI WILAYAH KERJA PUSKESMAS KOTA PADANG
}

\author{
The Relationship between Education and Knowledge with Decision of \\ Family Head in Delivery Help to Mother of Birth in Working Area \\ Kota Padang Public Health Center
}

\author{
Mika Oktarina ${ }^{1}$, Waytherlis Apriani ${ }^{1}$, Monalieca Harnita ${ }^{2}$ \\ ${ }^{1}$ Program Studi DIII Kebidanan STIKES Tri Mandiri Sakti Bengkulu \\ ${ }^{2}$ Program Studi DIV Kebidanan STIKES Tri Mandiri Sakti Bengkulu \\ Email : mikaoktarina165@gmail.com
}

\begin{abstract}
ABSTRAK
Pertolongan persalinan yang tepat akan meningkatkan derajat kesehatan ibu dan bayi yang dilahirkan sehingga penelitian ini bertujuan untuk mempelajari hubungan pendidikan dan pengetahuan dengan pengambilan keputusan kepala keluarga dalam pertolongan persalinan pada ibu bersalin di wilayah kerja Puskesmas Kota Padang. Penelitian ini menggunakan pendekatan deskriptif korelational dengan rancangan cross sectional. Populasi dalam penelitian ini seluruh kepala keluarga ibu bersalin di wilayah kerja Puskesmas Kota Padang tahun 2016 sebanyak 97 orang dengan menggunakan teknik pengambilan sampel Simple Random Sampling sehingga diperoleh 78 sampel. Pengumpulan data dalam penelitian ini yaitu menggunakan data primer dan sekunder. Analisis data dilakukan dengan analisis univariat dan bivariat dengan menggunakan uji statistic Chi-Square dan Contingency Coefficient. Hasil penelitian didapatkan : dari 78 kepala keluarga, terdapat 37 kepala keluarga (47,4\%) berpendidikan menengah, 35 kepala keluarga (44,9\%) berpengetahuan cukup, 47 kepala keluarga (60,3\%) menyatakan bahwa persalinan ditolong tenaga kesehatan, ada hubungan yang signifikan antara pendidikan dengan pengambilan keputusan pertolongan persalinan di wilayah kerja Puskesmas Kota Padang dengan kategori hubungan lemah, dan ada hubungan yang signifikan antara pengetahuan dengan pengambilan keputusan pertolongan persalinan di wilayah kerja Puskesmas Kota Padang dengan kategori hubungan sedang. Diharapkan kepada pihak Puskesmas untuk dapat meningkatkan pengetahuan dan wawasan masyarakat khususnya pada kepala keluarga tentang pentingnya melakukan pertolongan persalinan ke pelayanan kesehatan melalui penyuluhan dan penyebaran selebaran (leaflet) di wilayah kerja Puskesmas Kota Padang sehingga dapat menurunkan angka kematian ibu dan balita.
\end{abstract}

Kata Kunci : pendidikan, pengambilan keputusan, pengetahuan, persalinan 


\begin{abstract}
The appropriate delivery assistance will improve the maternal and baby health so that this study aimed to study the relationship between knowledge and education with the decision of the head of the family in the delivery aid to the maternal mother in the working area of Kota Padang Public Health Center. This study used correlational descriptive approach with cross sectional design. Population in this study was all head of maternal family in working area of Kota Padang Public Head Center 2016 counted 97 mother of birth by using Simple Random Sampling technique so that obtained 78 samples. Data collection in this study used primary and secondary data. Data analysis was done by univariate and bivariate analysis using Chi-Square and Contingency Coefficient statistic test. The results of the study were : from 78 heads of maternal family, there were 37 heads of maternal family (47.4\%) had medium education, 35 heads of maternal family (44.9\%) had enough knowledge, 47 heads of maternal family (60.3\%) said delivery was assisted by health personnel, a significant relationship between education and decision making of delivery aid in working area of Kota Padang Public Health Center with weak relation category, and there was a significant relationship between knowledge and decision of delivery aid in working area of Kota Padang Public Health Center with medium relation category. It was expected that Public Health Center would be able to increase the knowledge and insight of the community especially on the head of the family about the importance of delivering help to the health service through counseling and leaflet distribution in the working area of Kota Padang Public Health Center so that it could reduce maternal and infant mortality rate.
\end{abstract}

Keywords : childbirth, decision making, education, knowledge

\section{A. Pendahuluan}

Data

World

Health

Organization (WHO) menunjukkan

Angka Kematian Ibu (AKI) di dunia saat ini mencapai 289.000 jiwa. Angka kematian ibu di negara-negara Asia Tenggara, seperti Filipina 170 per 100.000 kelahiran hidup, Vietnam 160 per 100.000 kelahiran hidup, Thailand 44 per 100.000 kelahiran hidup, Brunei 60 per 100.000 kelahiran hidup (WHO, 2014).

Data Survey Demografi dan Kesehatan Indonesia (SDKI) tahun 2012, AKI (yang berkaitan dengan kehamilan, persalinan, dan nifas) sebesar 359 per 100.000 kelahiran hidup. Angka ini masih cukup tinggi jika dibandingkan dengan NegaraNegara tetangga di Kawasan ASEAN. AKI sudah mengalami penurunan, namun masih jauh dari target. (Kemenkes RI, 2015).

Laporan Dinas Kabupaten Rejang Lebong tahun 2015 jumlah ibu hamil pada sebanyak 5.381 orang dengan persalinan ditolong tenaga kesehatan sebanyak 4.730 orang dan ditolong bukan tenaga kesehatan sebanyak 651 orang dan pada tahun 2016 dari 5.301 ibu hamil terdapat 4.513 persalinan ditolong tenaga kesehatan dan 788 orang ibu hamil ditolong bukan tenaga kesehatan (Dinkes, 2016).

Berdasarkan data Dinas Kesehatan Rejang Lebong Tahun 2016 dari 21 Puskesmas dengan cakupan persalinan ditolong tenaga kesehatan tertinggi sebesar $109 \%$ berada di wilayah kerja puskesmas Puskesmas Sindang Kelingi Kecamatan Sindang 
Kelingi, sedangkan cakupan pertolongan persalinan oleh tenaga kesehatan terendah berada di wilayah kerja puskesmas Kota Padang sebesar 75,3\% (Dinkes, 2016).

Jumlah ibu hamil Puskesmas Kota Padang tahun 2015 dari 258 orang ibu bersalin sebanyak 157 orang persalinan ditolong tenaga kesehatan dan 101 bukan dengan tenaga kesehatan dengan Angka Kematian Ibu 5 orang dan tahun 2016 dari 254 ibu bersalin 183 orang persalinan ditolong tenaga kesehatan dan 71 orang bukan tenaga kesehatan dengan Angka Kematian Ibu (AKI) 4 orang.

Hasil Survey yang dilakukan pada tangga 25 Maret 2017 di wilayah kerja Puskesmas Kota Padang dari 10 kepala keluarga terdapat 7 orang kepala keluarga memilih melakukan pertolongan persalinan di rumah tanpa pertolongan petugas kesehatan dan 3 orang dilakukan di petugas kesehatan. Dari 7 orang kepala keluarga tersebut 5 orang lulusan SD dan 2 orang tidak lulus sekolah dan dari 7 orang tersebut rata-rata tidak memahami tentang pentingnya pertolongan persalinan oleh tenaga kesehatan.

Rumusan masalah penelitiann ini adalah "Apakah ada hubungan pendidikan dan pengetahuan dengan pengambilan keputusan kepala keluarga dalam pertolongan persalinan pada ibu bersalin di wilayah kerja
Puskesmas Kota Padang?. Tujuan penelitian mempelajari hubungan pendidikan dan pengetahuan dengan pengambilan keputusan kepala keluarga dalam pertolongan persalinan pada ibu bersalin di wilayah kerja Puskesmas Kota Padang.

\section{B. Metode Penelitian}

Jenis penelitian yang digunakan pada penelitian ini adalah kuantitatif metode deskriftip korelasi dengan rancangan cross sectional. Populasi dalam penelitian ini adalah seluruh kepala keluarga ibu bersalin di wilayah kerja Puskesmas Kota Padang tahun 2016 sebanyak 97 orang. Teknik pengambilan sampel secara simple random sampling. Pengumpulan data dalam penelitian ini dilakukan secara primer dan skunder. Analisis data menggunakan analisis univariat dan analisis bivariate menggunakan uji statistik Chi-Square $\left(\chi^{2}\right)$ dan Contingency Coefficient (C).

\section{Hasil Penelitian \\ 1. Analisis Univariat}

Dilakukan untuk mendapatkan distribusi frekuensi variabel independent (pendidikan dan pengetahuan) dan variabel dependent (pengambilan keputusan pertolongan persalinan) diperoleh data sebagai berikut :

Tabel 1

Distribusi Frekuensi Pendidikan Ibu di Wilayah Kerja Puskesmas Kota Padang

\begin{tabular}{ccc}
\hline Pendidikan & Frekuensi & Persentase $(\%)$ \\
\hline Dasar & 25 & 32,1 \\
Menengah & 37 & 47,4 \\
Tinggi & 16 & 20,5 \\
Total & 78 & 100,0 \\
\hline
\end{tabular}

Berdasarkan Tabel 2 berpendidikan dasar, 37 sampel menunjukkan bahwa dari 78 sampel, $(47,4 \%)$ berpendidikan menengah, dan terdapat 25 sampel $\quad(32,1 \%) \quad 6$ sampel $(20,5 \%)$ berpendidikan tinggi. 
Tabel 2

Distribusi Frekuensi Pengetahuan Ibu di Wilayah Kerja Puskesmas Kota Padang

\begin{tabular}{ccc}
\hline Pengetahuan & Frekuensi & Persentase $(\%)$ \\
\hline Kurang & 23 & 29,5 \\
Cukup & 35 & 44,9 \\
Baik & 20 & 25,6 \\
Total & 78 & 100,0 \\
\hline
\end{tabular}

Berdasarkan Tabel 2 berpengetahuan kurang, 35 sampel menunjukkan bahwa dari 78 sampel, (44,9\%) berpengetahuan cukup dan 20 terdapat 23 sampel $(29,5 \%)$ sampel $(25,6 \%)$ berpengetahuan baik.

Tabel 3

Distribusi Frekuensi Pengambilan Keputusan Pertolongan Persalinan di Wilayah Kerja Puskesmas Kota Padang

\begin{tabular}{ccc}
\hline Pengambilan Keputusan & Frekuensi & Persentase (\%) \\
Pertolongan Persalinan & 31 & 39,7 \\
Bukan Tenaga Kesehatan & 47 & 60,3 \\
Tenaga Kesehatan & 78 & 100,0 \\
Total &
\end{tabular}

Berdasarkan Tabel 3 menunjukkan bahwa dari 78 sampel, terdapat 31 sampel $\quad(39,7 \%)$ menyatakan bahwa persalinan ditolong bukan tenaga kesehatan dan 47 sampel $(60,3 \%)$ menyatakan persalinan ditolong tenaga kesehatan.

\section{Analisis Bivariat}

Dilakukan untuk mengetahui hubungan variabel independent pendidikan dan pengetahuan dan variabel dependent pengambilan keputusan pertolongan persalinan diperoleh data sebagai berikut :

Tabel 4

Hubungan Pendidikan dengan Pengambilan Keputusan Pertolongan Persalinan di Wilayah Kerja Puskesmas Kota Padang

\begin{tabular}{|c|c|c|c|c|c|c|c|c|c|}
\hline \multirow{3}{*}{ Pendidikan } & \multicolumn{6}{|c|}{$\begin{array}{c}\text { Pengambilan Keputusan Pertolongan } \\
\text { Persalinan } \\
\end{array}$} & \multirow{3}{*}{$\chi^{2}$} & \multirow{3}{*}{$p$} & \multirow{3}{*}{$C$} \\
\hline & \multicolumn{2}{|c|}{$\begin{array}{c}\text { Bukan Tenaga } \\
\text { Kesehatan }\end{array}$} & \multicolumn{2}{|c|}{$\begin{array}{c}\text { Tenaga } \\
\text { Kesehatan }\end{array}$} & \multicolumn{2}{|c|}{ Total } & & & \\
\hline & $\mathrm{F}$ & $\%$ & $\mathrm{~F}$ & $\%$ & $\mathrm{~F}$ & $\%$ & & & \\
\hline Dasar & 17 & 68,0 & 8 & 32,0 & 25 & 100 & & & \\
\hline Menengah & 11 & 29,7 & 26 & 70,3 & 37 & 100 & 12,82 & רחת & 0276 \\
\hline Tinggi & 3 & 18,8 & 13 & 81,2 & 16 & 100 & 9 & 002 & סו \\
\hline Total & 31 & 39,7 & 47 & 60,3 & 78 & 100 & & & \\
\hline
\end{tabular}


Berdasarkan Tabel $4 \quad$ Hasil uji statistik Pearson Chimenunjukkan tabulasi silang antara Square didapat nilai $\chi^{2}=12.829$ pendidikan dengan pengambilan dengan $\mathrm{p}=0,002<\alpha=0,05$ berarti keputusan pertolongan persalinan, signifikan, maka Ho ditolak Ha ternyata dari 25 orang pendidikan dasar diterima. Jadi terdapat hubungan yang terdapat 17 orang memutuskan signifikan antara pendidikan dengan persalinan ditolong bukan tenaga Pengambilan keputusan pertolongan kesehatan dan 8 orang memutuskan persalinan di Wilayah Kerja Puskesmas ditolong tenaga kesehatan, dari 37 Kota Padang. Hasil uji Contingency orang pendidikan menengah terdapat Coefficient didapat nilai $\mathrm{C}=0,376$ 11 orang memutuskan persalinan dengan $\rho=0,002<\alpha=0,05$ berarti ditolong bukan tenaga kesehatan dan signifikan, nilai $\mathrm{C}$ tersebut 26 orang memutuskan ditolong tenaga dibandingkan dengan nilai $\mathrm{C}_{\max }=$ kesehatan dan dari 16 orang pendidikan 0,707 (karena nilai terendah dari baris tinggi terdapat 3 orang memutuskan atau kolom adalah 2). Karena nilai C persalinan ditolong bukan tenaga jauh dengan nilai $\mathrm{C}_{\max }=0,707$ maka kesehatan dan 13 orang memutuskan katagori hubungan lemah.

ditolong tenaga kesehatan.

Tabel 5

Hubungan Pengetahuan dengan Pengambilan Keputusan Pertolongan Persalinan di Wilayah Kerja Puskesmas Kota Padang

Pengambilan Keputusan Pertolongan

Persalinan

\begin{tabular}{|c|c|c|c|c|c|c|c|c|c|}
\hline \multirow[t]{2}{*}{ Pengetahuan } & \multicolumn{2}{|c|}{$\begin{array}{c}\text { Bukan Tenaga } \\
\text { Kesehatan }\end{array}$} & \multicolumn{2}{|c|}{$\begin{array}{c}\text { Tenaga } \\
\text { Kesehatan }\end{array}$} & \multicolumn{2}{|c|}{ Total } & \multirow[t]{2}{*}{$\chi^{2}$} & \multirow[t]{2}{*}{$p$} & \multirow[t]{2}{*}{$C$} \\
\hline & $\mathrm{F}$ & $\%$ & $\mathrm{~F}$ & $\%$ & $\mathrm{~F}$ & $\%$ & & & \\
\hline Kurang & 18 & 78,3 & 5 & 21,7 & 23 & 100 & \multirow{4}{*}{21,186} & \multirow{4}{*}{0,000} & \multirow{4}{*}{0,462} \\
\hline Cukup & 10 & 28,6 & 25 & 71,4 & 35 & 100 & & & \\
\hline Baik & 3 & 15,0 & 17 & 85,0 & 20 & 100 & & & \\
\hline Total & 31 & 39,7 & 47 & 60,3 & 78 & 100 & & & \\
\hline
\end{tabular}

Berdasarkan Tabel 5 di menunjukkan tabulasi silang antara pengetahuan dengan pengambilan keputusan pertolongan persalinan, ternyata dari 23 orang pengetahuan kurang terdapat 18 orang memutuskan persalinan ditolong bukan tenaga kesehatan dan 5 orang memutuskan ditolong tenaga kesehatan, dari 35 orang pengetahuan cukup terdapat 10 orang memutuskan persalinan ditolong bukan tenaga kesehatan dan 25 orang memutuskan ditolong tenaga kesehatan dan dari 20 orang pengetahuan baik terdapat 3 orang memutuskan persalinan ditolong bukan tenaga kesehatan dan 17 orang memutuskan ditolong tenaga kesehatan.

Hasil uji statistik Pearson ChiSquare didapat nilai $\chi^{2}=21.186$ dengan $\rho=0,000<\alpha=0,05$ berarti signifikan, maka Ho ditolak Ha diterima. Jadi terdapat hubungan yang signifikan antara pengetahuan dengan pengambilan keputusan pertolongan persalinan di Wilayah Kerja Puskesmas Kota Padang. Hasil uji Contingency Coefficient didapat nilai $\mathrm{C}=0,462$ dengan $\rho=0,012<\alpha=0,05$ berarti signifikan, nilai $C$ tersebut 
dibandingkan dengan nilai yang dapat mempengaruhi $\mathrm{C}_{\max }=0,707$ (karena nilai terendah dari pengambilan keputusan pertolongan baris atau kolom adalah 2). Karena persalinan selain status pendidikan nilai $\mathrm{C}$ tidak jauh dengan nilai $\mathrm{C}_{\max }=$ diantaranya pelayanan yang diberikan 0,707 maka katagori hubungan sedang. petugas kesehatan. Hasil penelitian ini

\section{Pembahasan}

Hasil penelitian dari 25 orang pendidikan dasar terdapat 8 orang kepala keluarga memutuskan ditolong tenaga kesehatan yaitu Tn.G, Tn.F, Tn.S, Tn.W dan Tn.O karena kepala keluarga memiliki lokasi rumah yang berdekatan dengan pelayanan kesehatan, sedangkan Tn.Q, Tn.U dan Tn.D memiliki saudara yang berprofesi sebagai petugas kesehatan dan ekonomi menengah sehingga memutuskan persalinan pada tenaga kesehatan.

Hasil penelitian dari 16 orang pendidikan tinggi terdapat 3 orang persalinan ditolong bukan tenaga kesehatan Tn.A, Tn.N dan Tn.T karena tinggal diperkebunan sehingga jarak rumah dengan pusat kesehatan pelayanan kesehatan jauh dan kepala keluarga memutuskan untuk memanggil dukun untuk melakukan pertolongan persalinan dirumah.

Hasil uji statistik Pearson ChiSquare terdapat hubungan yang signifikan antara pendidikan dengan pengambilan keputusan pertolongan persalinan. Hasil penelitian ini sejalan dengan pendapat Juariah (2011), tingkat pendidikan seseorang akan berpengaruh dalam memberikan respon terhadap sesuatu yang datang dari luar. Orang yang berpendidikan tinggi akan memberikan respon yang lebih rasional terhadap informasi yang datang dan alasan berfikir sejauh mana keuntungan yang mungkinakan mereka peroleh dari gagasan tersebut.

Hasil uji Contingency Coefficient didapat katagori hubungan lemah. Kategori hubungan lemah menunjukkan bahwa ada faktor lain faktor pengetahuan sangat besar faktor pengetahuan sangat besar pengaruhnya terhadap pertolongan persalinan di sarana pelayanan. Banyak keluarga yang salah pemahaman bahwa di pelayanan kesehatan masih ada unsur "diskriminasi" perlakuan pelayanan kesehatan meski ini juga konsekuensi pilihannya. Sejak awal masuk pelayanan kesehatan, ibu dan bayi telah dibeda-bedakan menurut kelas-kelas perawatannya kelak, perlakuan pihak pelayanan kesehatan bisa dikatakan kurang personal atau tidak "ramah.

Hasil penelitian dari 23 orang pengetahuan kurang terdapat 5 orang kepala keluarga memutuskan ditolong tenaga kesehatan yaitu Tn.R, Tn.G dan Tn.S karena lokasi rumah dekat dengan fasilitas kesehatan, sedangkan Tn.U dan Tn.U karena memiliki saudara petugas kesehatan dan semua kepala keluarga dengan ekonomi menengah sehingga memilih petugas kesehatan.

Hasil penelitian dari 20 orang pengetahuan baik terdapat 3 orang kepala keluarga memutuskan persalinan dilakukan bukan pada tenaga kesehatan yaitu Tn.W, Tn.K dan Tn.L karena tinggal diperkebunan dengan lokasi jauh dari pelayanan kesehatan sehingga memutuskan persalinan ditolong bukan tenaga kesehatan (dukun).

Hasil uji statistik Pearson ChiSquare terdapat hubungan yang signifikan antara pengetahuan dengan pengambilan keputusan pertolongan persalinan. Hasil penelitian ini sejalan dengan pendapat Notoatmodjo (2012), pengetahuan merupakan faktor yang penting untuk terbentuknya perilaku 
seseorang, karena pengalaman dan penelitian terbukti bahwa perilaku yang didasari pengetahuan akan lebih langgeng dari perilaku yang tidak didasari oleh pengetahuan. Dengan meningkatnya pengetahuan kepala keluarga tentang kesehatan diharapkan kepala keluarga dapat memutuskan tempat pemilihan persalinan yang tepat.

Hasil uji Contingency Coefficient didapat katagori hubungan sedang. Kategori hubungan sedang menunjukkan bahwa ada faktor lain yang dapat mempengaruhi pengambilan keputusan pertolongan persalinan selain status pengetahuan yaitu pelayanan petugas kesehatan. Hasil penelitian ini sejalan dengan teori Echa (2013), faktor pengetahuan sangat besar pengaruhnya terhadap pertolongan persalinan di sarana pelayanan. Banyak keluarga yang salah pemahaman bahwa di pelayanan kesehatan masih ada unsur "diskriminasi" perlakuan pelayanan kesehatan meski ini juga konsekuensi pilihannya. Sejak awal masuk pelayanan kesehatan, ibu dan bayi telah dibeda-bedakan menurut kelas-kelas perawatannya kelak, perlakuan pihak pelayanan kesehatan bisa dikatakan kurang personal atau tidak ramah.

\section{E. Kesimpulan}

1. Dari 78 sampel, 37 sampel $(47,4 \%)$ berpendidikan menengah di wilayah kerja Puskesmas Kota Padang.

2. Dari 78 sampel, terdapat 35 sampel (44,9\%) berpengetahuan cukup di wilayah kerja Puskesmas Kota Padang.

3. Dari 78 sampel, terdapat 47 sampel $(60,3 \%)$ menyatakan bahwa persalinan ditolong tenaga kesehatan di wilayah kerja Puskesmas Kota Padang.
4. Ada hubungan yang signifikan antara pendidikan dengan pengambilan keputusan pertolongan persalinan di wilayah kerja Puskesmas Kota Padang, dengan kategori hubungan lemah.

5. Ada hubungan yang signifikan antara pengetahuan dengan Pengambilan keputusan pertolongan persalinan di wilayah kerja Puskesmas Kota Padang, dengan kategori hubungan sedang.

\section{Daftar Pustaka}

Echa, A. (2013). Tingkat Pengetahuan Ibu Hamil Trimester III Tentang Antenatal Care di RSUD Surakarta Tahun 2013. Karya Tulis Ilmiah.

Kemenkes RI. (2015). Profil Kesehatan Indonesia 2014. Jakarta : Kemenkes RI.

Notoatmodjo, S. (2012). Promosi Kesehatan dan Ilmu Perilaku edisi revisi. Jakarta : Rineka Cipta.

(2012). Pendidikan dan Perilaku Kesehatan Edisi Revisi. Jakarta : Rineka Cipta.

WHO. (2014). Maternal Mortality Database in World. Swizerland : WHO Press. 